\title{
Human mammary gland and breast carcinoma contain immunoreactive inhibin/activin subunits: evidence for a secretion into cystic fluid
}

\author{
C Di Loreto ${ }^{1}$, F M Reis, P Cataldi ${ }^{1}$, C Zuiani ${ }^{2}$, S Luisi, C A Beltrami ${ }^{1}$ and F Petraglia \\ Department of Surgical Sciences, Chair of Obstetrics and Gynecology, and Department of Medical and Morphological Research, \\ ${ }^{1}$ Chair of Pathology and ${ }^{2}$ Chair of Radiology, University of Udine, Udine, Italy \\ (Correspondence should be addressed to F Petraglia, Department of Surgical Sciences, Chair of Obstetrics and Gynecology, University of Udine, \\ Piazz.le S. Maria della Misericordia, 33100 Udine, Italy; Email: Felice.Petraglia@DSC.Uniud.it)
}

\begin{abstract}
Objective: Inhibins and activins are members of the transforming growth factor $\beta$ superfamily and are known to modulate the growth and differentiation of several cell types. The present study investigated the localization of inhibin and activin subunits in human normal and pathological breast tissues. Design: A cross-sectional study comparing the expression of inhibin/activin subunits $\alpha, \beta \mathrm{A}$ and $\beta \mathrm{B}$ in surgical specimens from women undergoing reductive mammoplasty (classified, according to the phase of the menstrual cycle, as follicular, luteal, or postmenopausal), and patients submitted to lumpectomy for fibrocystic disease, benign (intraductal papilloma, adenomyoepithelioma, and hamartoma) or malignant breast neoplams (intraductal, intralobular, and invasive carcinoma).

Methods: Immunohistochemistry was used to localize inhibin $\alpha$ and activin $\beta \mathrm{A}$ and $\beta \mathrm{B}$ subunits in the cytoplasm of epithelial cells of mammary glands. Dimeric activin A, inhibin A and inhibin B were measured by specific two-site enzyme immunoassay in the cystic fluid collected from patients with fibrocystic disease.

Results: An intense staining for the $\alpha$ inhibin subunit and a mild staining for $\beta \mathrm{A}$ and $\beta \mathrm{B}$ subunits were present in samples obtained from normal breast tissue regardless of menstrual cycle phase, and in fibrocystic disease and benign neoplasms. Carcinoma cells stained weakly to moderately for $\alpha$ subunit and were negative for $\beta \mathrm{A}$ and $\beta \mathrm{B}$ subunits. Fibrocystic disease was associated with absence of $\beta \mathrm{A}$ subunit expression in normal epithelial cells and intense staining for all subunits in the apocrine cells. Immunoreactive inhibin A, inhibin B, and activin A were also present in cystic fluid, suggesting a local secretion of these proteins.

Conclusion: These data suggest a local expression and secretion of inhibin and activin in human normal, fibrocystic disease and neoplastic breast tissues. The low expression of these proteins may facilitate abnormal cell proliferation in breast carcinoma.
\end{abstract}

European Journal of Endocrinology 141 190-194

\section{Introduction}

Inhibins and activins are dimeric proteins that share a considerable sequence homology with the transforming growth factor- $\beta$ family (1). Inhibin is a $32 \mathrm{kDa}$ heterodimer composed of an $\alpha$ subunit and one of two $\beta$ subunits, named $\beta \mathrm{A}$ and $\beta \mathrm{B}$, which characterize inhibin $A$ and $B$ respectively. The dimerization of two inhibin $\beta$ subunits gives rise to activin $A(\beta A-\beta A)$, activin $\mathrm{B}(\beta \mathrm{B}-\beta \mathrm{B})$ or activin $\mathrm{AB}(\beta \mathrm{A}-\beta \mathrm{B})$.

Inhibin was initially isolated from the gonads and identified as modulator of the release of follicle-stimulating hormone from the anterior pituitary gland (1). Recent studies indicated that inhibin and activin are expressed in a wide variety of tissues and have a critical role in growth and developmental mechanisms, modulating the proliferation and differentiation of several cell types $(2,3)$. The expression and secretion of inhibin and related proteins in various tumours is currently under investigation (4-10). The tumoral secretion of inhibin and activin into systemic circulation is suggested by the high serum levels of immunoreactive inhibin in women with ovarian or placental carcinoma $(4,5)$, and by the high levels of serum activin A associated with solid tumours $(9,10)$.

Inhibins and activins seem to participate in the differentiation of mammary epithelial cells (11) and in the growth and morphogenesis of primary or transformed mammary epithelial cells $(12,13)$. In spite of the putative relevance of inhibin-related proteins to the 
control of breast cancer development, the local expression of these proteins in breast lesions is still unknown.

In order to find out whether mammary epithelial cells express these proteins in normal and in pathological conditions, we investigated the localization of immunoreactive inhibin and activin subunits in histological specimens of healthy breast tissue, benign lesions and breast cancer. An additional objective of this study was to verify whether dimeric inhibin A, inhibin B and activin $A$ are secreted into the cystic fluid of benign adenomatous cysts.

\section{Materials and methods}

\section{Patients}

Informed consent was obtained from all participants and the study was approved by the institutional Human Investigation Committee. A sample of women $(n=31)$ submitted to reduction mammoplasty $(n=14)$ or surgical lumpectomy for symptomatic lesions $(n=17)$ was studied. The patients who underwent reduction mammoplasty were divided into three groups according to the stage of their menstrual cycle: 1) women in the follicular phase ( $n=5$, age range $21-47$ years); 2 ) women in the luteal phase $(n=5$ patients, age range 23-41 years); and 3) women in postmenopause $(n=4$, age range 59-64 years). All patients enrolled in the first two groups had regular menstrual cycles and the cycle phase was determined by the last menstrual period.

The surgically resected lesions of the 17 patients in this group (age range 30-58 years) were diagnosed as follows: a) fibrocystic disease $(n=5)$; b) benign tumours $(n=5)$ comprising intraductal papilloma $(n=3)$, adenomyoepithelioma $(n=1)$, and breast hamartoma $(n=1)$; c) breast carcinoma $(n=7)$ including intraductal carcinoma $(n=2)$, intralobular carcinoma $(n=1)$, invasive ductal carcinoma $(n=3)$, and invasive tubulolobular carcinoma $(n=1)$.

Cystic fluid samples were collected by needle aspiration from patients with fibrocystic disease $(n=5$, age range $42-51$ years) and stored at $-20^{\circ} \mathrm{C}$ until assayed for activin A, inhibin A and inhibin $\mathrm{B}$ concentrations.

\section{Tissue collection and immunohistochemistry}

The tissue samples were fixed in $10 \%$ buffered formalin, embedded in paraffin and processed routinely. To improve antigen retrieval, paraffin sections were rehydrated and heated in a microwave oven $(800 \mathrm{~W}$ for $5 \mathrm{~min}$ and $300 \mathrm{~W}$ for $10 \mathrm{~min}$ ) using $0.01 \mathrm{~mol} / \mathrm{l}$ citrate buffer, pH 7.3. All sections were stained by the peroxidase-streptavidin-biotin technique. Briefly, after blockade of endogenous peroxidase, the sections were incubated overnight with the primary antibody, followed by biotinylated link antibodies and peroxidase streptavidin (LSABTM, Dako, Glostrup, Denmark) for
30 min each. After the development of peroxidase with diaminobenzidine, the slides were counterstained in Mayer's haematoxylin, dehydrated and mounted in Eukitt.

The following highly specific antisera were used: rabbit anti- $\alpha(1-26)$-Gly-Tyr diluted 1:100, mouse anti$\beta \mathrm{A}(81-113)-\mathrm{NH}_{2}$, and mouse anti- $\beta \mathrm{B}(81-112)-\mathrm{NH}_{2}$ diluted 1:25. These were affinity purified polyclonal antisera raised against synthetic peptide fragments and kindly donated by Dr W Vale (Salk Institute, San Diego, USA). Their characteristics have previously been described in detail (14) and no cross-reaction between the three antisera has been observed.

Positive controls were carried out using standard positive placental sections stained with the specific antibodies. Negative controls consisted of breast tissue sections in which the primary antibody was replaced by non-immune rabbit or mouse serum. The immunostaining was evaluated by estimating the distribution and the intensity of positive cells. A positive reaction was characterized by the presence of granular brown staining in the cytoplasm. Intensity of staining was graded semiquantitatively on a scale of $0-3$ arbitrary units, with 0 indicating no detectable staining, $1=$ weak, $2=$ moderate, and $3=$ strong immunostaining.

\section{Inhibin $A$, inhibin $B$, and activin $A$ assays}

Inhibin A, inhibin B and activin A concentrations in breast cystic fluid were measured, as previously described (9), by specific two-site enzyme immunoassays purchased from Serotec (Oxford, UK). The inhibin A detection limit was $20 \mathrm{pg} / \mathrm{ml}$ serum, with intra- and interassay coefficients of variations $(\mathrm{CV})$ for quality control samples less than $4.0 \%$ and $8.0 \%$ respectively. The assay limit of detection for inhibin B was less than $30 \mathrm{pg} / \mathrm{ml}$ in serum and less than $15 \mathrm{pg} / \mathrm{ml}$ in cystic fluid. Within- and between-plate CVs in this case were less than $5.0 \%$ and $9.0 \%$ respectively. The limit of detection for activin A was less than $100 \mathrm{pg} / \mathrm{ml}$, and intra- and interassay CVs were $5.0 \%$ and $9.0 \%$, respectively. Cross-reactions for each assay with the various inhibin-related proteins were less than $0.5 \%$.

\section{Statistical analysis}

The concentrations of dimeric activin and inhibin in cystic fluid are reported as means \pm standard deviations (s.D.). The intensity of immunostaining for inhibin/activin subunits is expressed as medians and ranges, and differences between groups were assessed by Kruskal-Wallis analysis of variance followed by Dunn's test for non-parametric multiple comparisons.

\section{Results}

In normal breast tissue, ductal and lobular epithelial cells were strongly immunoreactive for $\alpha$ antiserum 

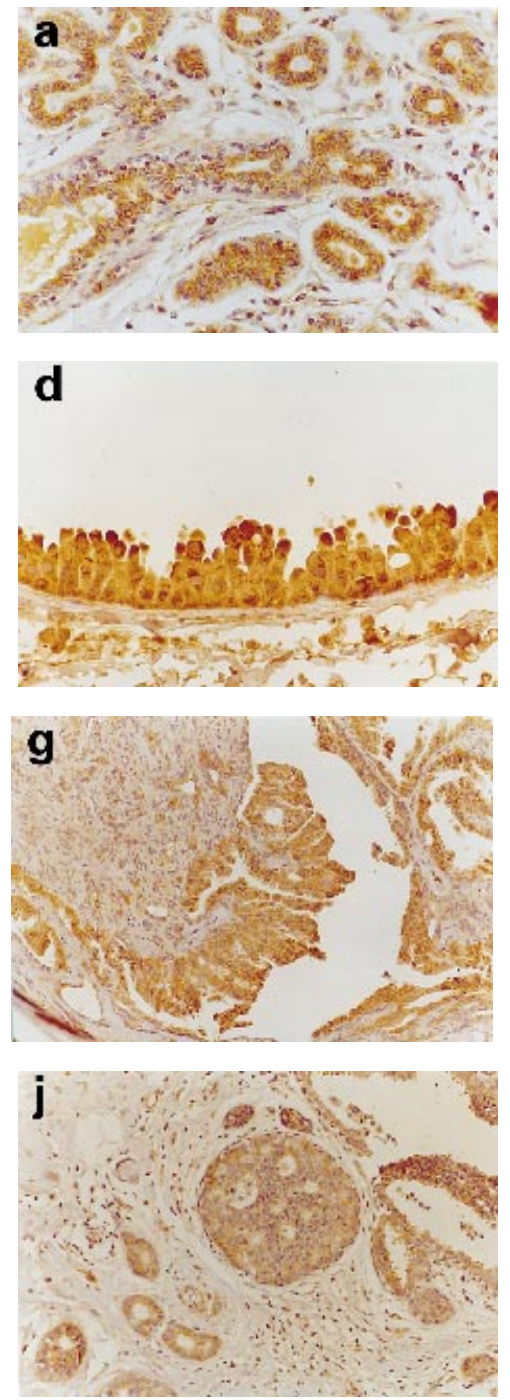
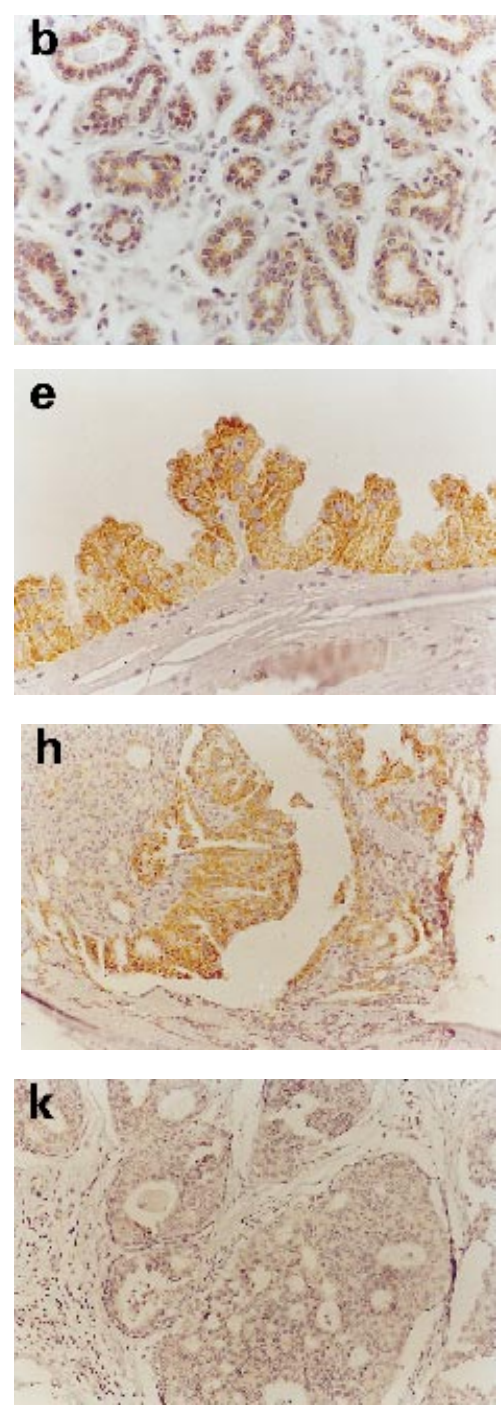
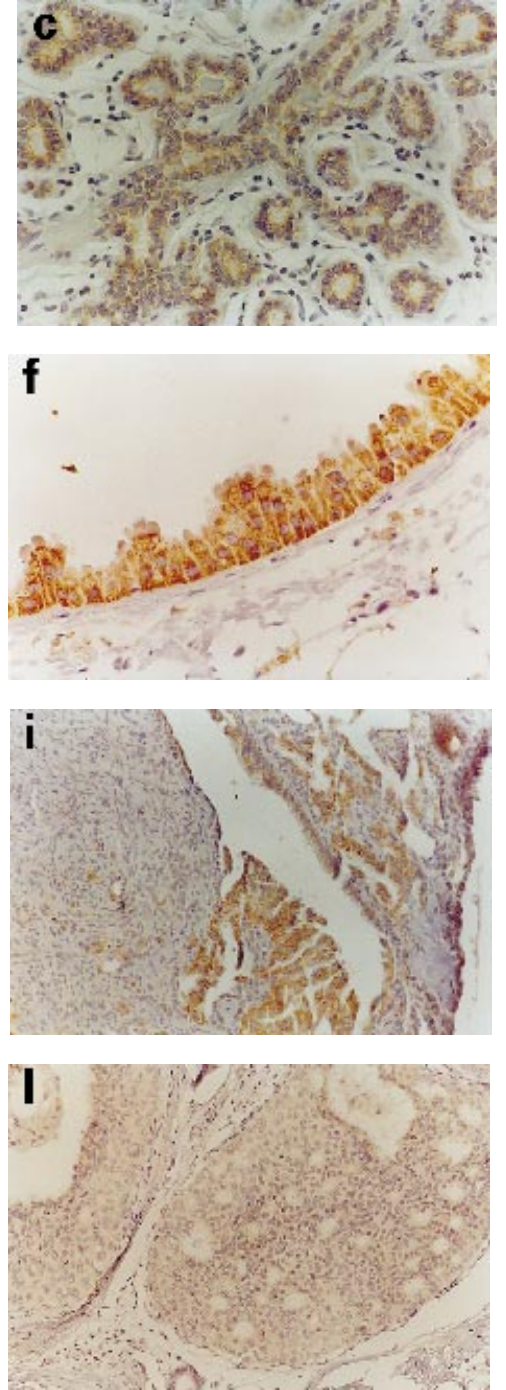

Figure 1 Representative examples of mammary tissue immunostained for inhibin/activin subunits $\alpha$ (left: a, d, g, j), $\beta$ A (centre: b, e, h, k), and $\beta \mathrm{B}$ (right: $\mathrm{c}, \mathrm{f}, \mathrm{i}, \mathrm{I})$. Breast tissue samples were obtained from surgical resection of normal mammary tissue (a-c), fibrocystic disease $(d-f)$, benign adenomyoepithelioma $(g-i)$, and intraductal carcinoma $(j-l)$. Specific immunostaining is indicated by the presence of granular brown staining in the cytoplasm. Original magnifications were $\times 400(a-f)$ and $\times 250(g-l)$.

and weakly positive for $\beta \mathrm{A}$ and $\beta \mathrm{B}$ antibodies (Fig. 1). No immunoreactivity was seen in the myoepithelial cells, contrasting with the strong $\alpha$ subunit immunostaining observed in the endothelial cells. No difference between the phases of the menstrual cycle was found; however, there was a moderate decrease of intensity of staining for $\alpha$ subunit in menopausal women $(P<0.05$, Fig. 2). Negative controls failed to show any immunostaining for the three antigens tested.

In the benign neoplasms, epithelial cells were moderately or strongly positive for $\alpha$ subunit antiserum and weakly stained for $\beta \mathrm{B}$ and $\beta \mathrm{A}$ subunits. Apocrine epithelial cells in the fibrocystic disease showed an intense immunostaining for all antigens (Fig. 1), whereas normal epithelial cells around the cysts were faintly stained for $\beta \mathrm{B}$ and negative for $\beta \mathrm{A}$ subunit. In the malignant lesions, the epithelial neoplastic cells expressed a weak to moderate positivity for $\alpha$ subunit antiserum, but were negative for $\beta \mathrm{A}$ and $\beta \mathrm{B}$ subunits, contrasting with the pattern observed in normal breast tissue $(P<0.05$, Fig. 2$)$. Endothelial cells were positive only for $\alpha$ subunit antiserum.

As shown in Fig. 3, measurable concentrations of dimeric activin A, inhibin A and inhibin B were found in cystic fluid samples from patients with fibrocystic disease. The concentrations of activin A $(150 \pm 40 \mathrm{pg} / \mathrm{ml})$ were greater than those of inhibin A $(114 \pm 17 \mathrm{pg} / \mathrm{ml})$ and inhibin B $(35 \pm 15 \mathrm{pg} / \mathrm{ml})$. 


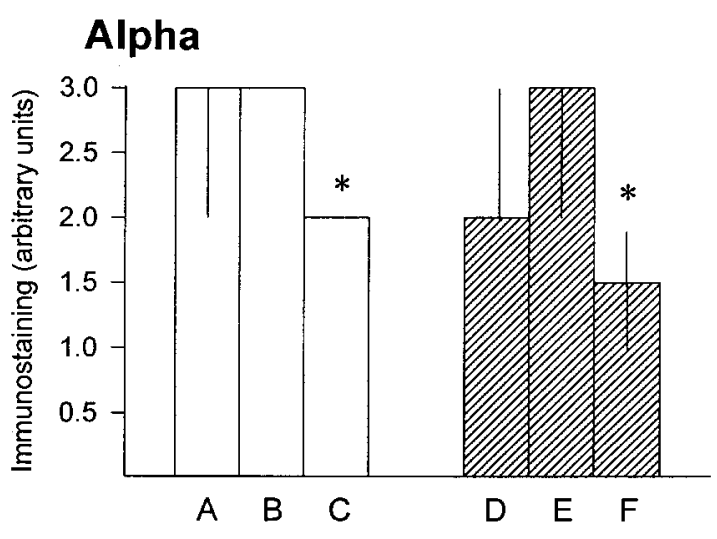

Beta A

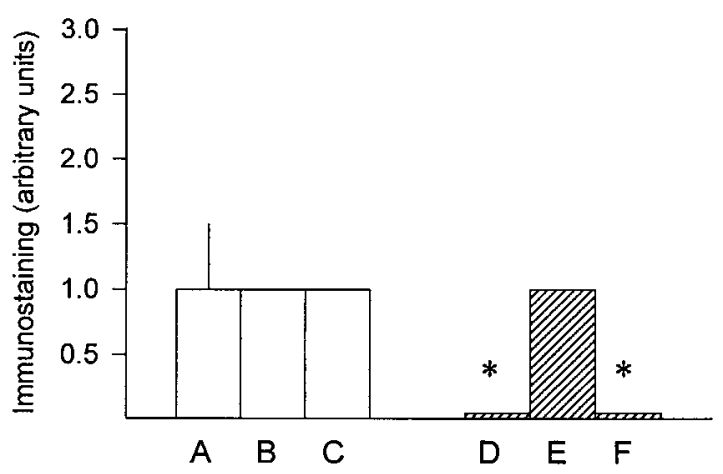

Beta B

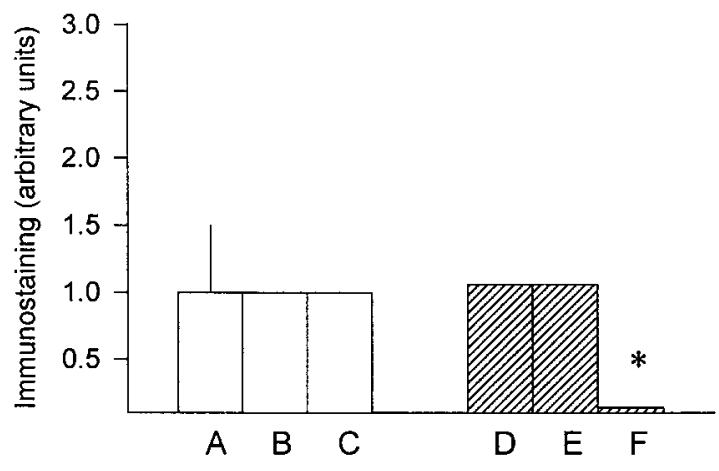

Figure 2 Immunostaining for inhibin/activin subunits $\alpha$ (Alpha), $\beta \mathrm{A}$ (Beta $\mathrm{A}$ ) and $\beta \mathrm{B}$ (Beta $\mathrm{B}$ ) in epithelial cells of normal breast tissue resected in the proliferative $(A)$ or secretory $(B)$ phases of the menstrual cycle, or from postmenopausal women (C), compared with breast disorders: fibrocystic disease (D), benign tumours $(E)$ and breast carcinoma $(F)$. Data are expressed as medians \pm ranges. ${ }^{*} P<0.05$ compared with controls, proliferative phase (Dunn's test).

\section{Discussion}

This is the first demonstration that inhibin and activin $\alpha$ and $\beta$ subunits are expressed in human breast tissue. Normal breast tissue expressed inhibin/activin $\alpha, \beta \mathrm{A}$ and $\beta \mathrm{B}$ subunits without showing variation during the

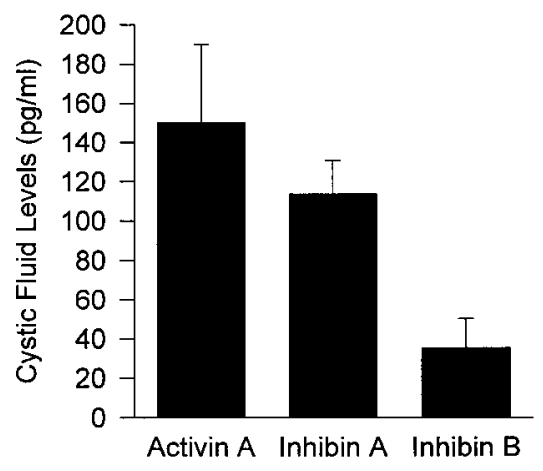

Figure 3 Levels of inhibin A, inhibin B and activin A dimers in samples of cystic fluid from women with fibrocystic disease. Data are reported as means \pm S.D. $(n=5)$.

menstrual cycle, with a slight reduction of $\alpha$ subunit signal in samples from postmenopausal women. Conversely, neoplastic epithelial cells lacked $\beta \mathrm{A}$ and $\beta \mathrm{B}$ expression while showing a low level of staining for immunoreactive $\alpha$ subunit. These findings suggest that ductal and lobular epithelial cells normally produce inhibin-related peptides, possibly under regulatory mechanisms independent of menstrual-cycle-related changes in circulating sex hormones. Moreover, the present data indicate that the synthesis of inhibin/ activin subunits is modified in cells from invasive breast carcinoma.

The localization of immunoreactive inhibin/activin subunits in breast tissue suggests a local synthesis by mammary epithelial and endothelial cells, even though the immunohistochemical localization does not exclude the possibility that cells have captured the proteins from outside sources. Parallel identification of their respective messenger ribonucleic acid sequences is still required to confirm that inhibin/activin subunits are actually produced by breast cells in vivo. However, our data provide indirect evidence supporting a local production of activin and inhibin in the breast. The lack of differences during the menstrual cycle is in contrast with the cyclic changes that characterize serum inhibin concentrations (15). The presence of activin and inhibin dimers in cystic fluid more likely reflects local production and secretion, rather than a mere transudation from serum, because the circulating concentrations of activin $\mathrm{A}$ in fertile women are substantially lower than those of inhibin A and inhibin B (16), contrasting with the relatively higher activin A concentration found in cystic fluid. Furthermore, mRNA sequences encoding $\beta$ A subunit and activin RII receptor have been identified in selected populations of normal cultured human breast cells (12).

The physiological role of these peptides in the breast remains unknown. Nevertheless, the significance of decreased $\alpha$ and $\beta$ subunits in neoplastic cells is potentially relevant for tumour growth. The 
proliferation of breast cancer cell lines in vitro may be inhibited by activin $A$, and this mechanism is dependent on oestrogen receptor expression (17). The antiproliferative effect of human chorionic gonadotrophin on immortalized human breast epithelial cells is accompanied by the immunocytochemical expression of inhibin/activin $\alpha$ and $\beta$ subunits (18).

In conclusion, the present data suggest a different expression of inhibin/activin subunits in normal mammary epithelium, fibrocystic disease, and benign and malignant breast tumours. The low expression of these proteins in carcinoma tissue may facilitate abnormal cell proliferation.

\section{References}

1 Vale W, Rivier C, Hsueh A, Campen C, Meunier H, Bicsak T et al. Chemical and biochemical characterization of the inhibin family of protein hormones. Recent Progress in Hormone Research 1988 $441-34$

2 Ueno N, Nishimatsu S \& Murakami K. Activin as a cell differentiation factor. Progress in Growth Factor Research 19902 $113-124$.

3 Meunier H, Rivier C, Evans RM \& Vale W. Gonadal and extragonadal expression of inhibin $\alpha, \beta \mathrm{A}$, and $\beta \mathrm{B}$ subunits in various tissues predicts diverse functions. Proceedings of the National Academy of Sciences of the USA 198885 247-251.

4 Burger HG. Inhibin as a tumor marker. Clinical Endocrinology 199441 151-153.

5 Yohkaiichiya T, Fudaya T, Hoshiai H, Yajima A \& de Kretser DM. Inhibin, a new circulating marker in hydatiform mole. British Medical Journal 1989298 1684-1686.

6 Petraglia F, Luisi S, Pautier P, Sabourin JC, Rey R, Lhomme C \& Bidart JM. Inhibin B is the major form of inhibin/activin family secreted by granulosa cell tumors. Journal of Clinical Endocrinology and Metabolism 199883 1029-1032.

7 Di Simone N, Crowley WF, Wang QI-FA \& Scheyer AL. Characterization of inhibin/activin subunit, follistatin, and activin type II receptors in human ovarian cancer cell lines: a potential role in autocrine growth regulation. Endocrinology 1996137 486-494.

8 Alexander JM. Swearingen B, Tindall GT \& Klibanski A. Human pituitary adenomas express endogenous inhibin subunit and follistatin messenger ribonucleic acids. Journal of Clinical Endocrinology and Metabolism 199580 147-152.
9 Petraglia F, Florio P, Luisi S, Gallo R, Garducci A, Viganò P et al. Expression and secretion of inhibin and activin in normal and neoplastic uterine tissues. High levels of serum activin A in women with endometrial and cervical carcinoma. Journal of Clinical Endocrinology and Metabolism 199883 1194-1200.

10 Harada H, Shintani Y, Sakamoto M, Shitsukawa K \& Saito S. Serum immunoreactive activin A in normal subjects and patients with various diseases. Journal of Clinical Endocrinology and Metabolism 199681 2125-2130.

11 Robinson GW \& Hennighausen L. Inhibins and activins regulate mammary epithelial cell differentiation through mesenchymal-epithelial interactions. Development $1997 \mathbf{1 2 4}$ $2701-2708$.

12 Liu QY, Niranjan B, Gomes JJ, Davies D, Coombes RC \& Buluwela L. Inhibitory effects of activin on growth and morphogenesis of primary and transformed mammary epithelial cells. Cancer Research 199656 1155-1163.

13 de Winter JP, Roelen AJ, ten Dijke P, van der Burg B \& van den Eijnden-van Raaij AJ. DPC4 (SMAD4) mediates transforming growth factor- $\beta 1$ (TGF- $\beta 1$ ) induced growth inibition and transcriptional response in breast tumor cells. Oncogene 1997 14 1891-1899.

14 Vaughan JM, Rivier J, Corrigan AZ, McClintock R, Campen CA, Jolley D et al. Detection and purification of inhibin using antisera generated against synthetic peptide fragments. Methods in Enzymology $1989168588-601$.

15 Groome NP, Illingworth PJ, O'Brien M, Pai R, Rodger FE, Mether JP et al. Measurement of dimeric inhibin B throughout the human menstrual cycle. Journal of Clinical Endocrinology and Metabolism 199681 1401-1405.

16 Petraglia F, Hartmann B, Luisi S, Florio P, Santuz M, Kirchengast $\mathrm{S}$ et al. Low levels of serum inhibin A and inhibin B in women with hypergonadotropic amenorrhea and evidence of high levels of activin A in women with hypothalamic amenorrhea. Fertility and Sterility 1998 70 907-912.

17 Kalkhoven E, Roelen BA, de Winter JP, Mummery CL, van den Eijnden-van Raaij AJ, van der Saag PT et al. Resistance to transforming growth factor beta and activin due to reduced receptor expression in human breast tumor cell lines. Cell Growth and Differentiation 19956 1151-1161.

18 Ho TY \& Russo IH. Polypeptide pattern of human breast epithelial cells following human chorionic gonadotropin (hCG) treatment. Electrophoresis 199415 746-750.

Received 22 January 1999

Accepted 27 April 1999 